\title{
Use of Nanotechnology to Achieve the Best Functional Characteristics of the Fabrics Sheets Used in Hospitals
}

\author{
S.Sharaf ${ }^{1 *}$, Ola Abdel Salam Barakat ${ }^{2}$ \\ ${ }^{1}$ Textile Research Division, National Research Center(Scopus affiliation ID: \\ 60014618), El-Behouth St. (former El-Tahrir St.), Dokki, P.O. 12311, Giza, Egypt. \\ Cairo, Egypt. \\ ${ }^{2}$ Spinning and Weaving Dept., Faculty of Applied Arts, Helwan University, Egypt.
}

\begin{abstract}
$\mathbf{T}$ HIS RESEARCH aims to achieve the best functional characteristics of the bed sheets used by hospitals, to be resistant to bacteria, and have the ability to Self-Cleaning. Three fabrics were produced from different weft material (rayon, bamboo, and cotton) and were treated with Nanosilver, and Nano Titanium dioxide $\left(\mathrm{TiO}_{2}\right)$. Fabrics were coated with the nanoparticles in three different sequences: 1 ) coating of fabric with $1 \% \mathrm{TiO}_{2}$ nanoparticles and $\mathrm{Ag}$ nanoparticles in the same bath, 2) coating of fabric by $1 \% \mathrm{TiO}_{2}$ post-treated by $\mathrm{Ag}$ nanoparticles, 3) coating of fabric by $\mathrm{Ag}$ nanoparticles post-treated with $-1 \% \mathrm{TiO}_{2}$ treated fabric). Treated samples were tested for Pema test (skin model) and Stability of treatment to washing test. The results show that cotton and a little less bamboo are the best treated materials, achieved the high-performance efficiency for the purpose of use, where they gave the best properties directly associated with the comfort (water vapor permeability, air permeability, and thermal conductivity), after treatment with nano-materials . Also, the treatment of fabrics by $\mathrm{TiO}_{2}$ post-treated by silver nanoparticles solution shows higher antibacterial results than other two sequences of treatments, and Bamboo treated samples exhibited more significant efficacy against bacteria. Therefore, the treated fabric believed to have great potential for use as antibacterial fabrics to reduce the likelihood of being infected with the bed sores. All treated samples show high efficiency towards removal of MB dye stains, and bamboo treated samples are the most effective one towards the self-cleaning feature.
\end{abstract}

Keywords: Nanotechnology, Functional characteristics, Antimicrobial, Self-Cleaning, Sheet fabrics.

\section{Introduction}

Fabric properties depend on fiber properties, yarn structure, fabric structure and the mechanical and chemical finishing treatment.[1, 2]. Fiber properties such, fiber type, fineness, crosssectional shape, crimp, length, and surface properties are extremely important. Also, yarns structure such, spinning systems, twist, and a number of yarns govern with fiber properties in the yarn properties. Fabric structure includes yarn linear densities, set, and weave structure can influence critical fabric properties like weight, thickness, bulk, mechanical properties, and surface behavior,...... etc.[3].

Finishing affects the properties and appearance of the fabrics and can significantly change the performance of it. It can be physical, or chemical, temporary or permanent[4]. Conventional methods which used to impart different properties of fabrics often don't lead to permanent effects and will lose their function after using and washing.[5, 6]. Fabric finishing has taken new ways and demonstrated a great potency for significant improvements by applications of nanotechnology[6,7].

Nowadays there is a tendency for "bio, eco, natural and environmentally friendly". The development of bio-based formulations for finishing textiles is still a challenge and demands novel formulations[7].

"Corresponding author e-mail: samarsami2004@yahoo.com

DOI: 10.21608/EJCHEM.2018.2892.1238

C2017 National Information and Documentation Center (NIDOC) 
Important properties of sheet fabrics affecting the efficiency of their performance

There is a general agreement that the transmission of air, water vapor, and heat through fabrics are the most important factors in textile comfort.

\section{Moisture absorption}

It is the most important properties of fabrics sheets, where the patient's body secretes amount of sweat, humidity, and secretions associated with surgical operations permanently, which probably cause bed sores. Fiber absorption affects the overall comfort of the user.

One of the main factors that influence the absorption of sweat and humidity:

- The permeable fabric of water vapor.

- The ability of the fabric to absorb moisture inside the fibers physically and mechanically between the fibers and between the yarns.

- The generate heat from absorption of moisture inside the fibers.

- The ability of textile fabrics to dry $[6,8]$.

Water vapor Permeability and transmission of moisture:

Water vapor can pass through the fabric by the following:

- $\quad$ spreading water vapor across the fabric

- Adsorption and migration of water vapor along the fiber surface.

- Absorption, transport, and vapor of water vapor by fiber.

Transmission of moisture through textiles has a significant impact on the physiological and thermal comfort of the human body. Processes that play a great role in the transfer of moisture depending on the moisture content of the fabric, the type of materials used the rate of sweat and weather conditions, such as humidity, temperature and wind speed[8].

\section{Air permeability}

Air permeability is an important comfort property of the fabric. It determines the ability of air to flow through a fixed area of the fabric. Air permeability through textiles is mainly affected by the porosity of the fabrics[6]

\section{Thermal conductivity}

Thermal conductivity is the time rate of fixed heat flow through a unit area. Physiological comfort is connected with thermal comfort, which is considered as a state of satisfaction from the thermal conditions of the environment. Thermal comfort depends on many factors. There are many properties which influence the thermal comfort of the fabric user, as thermal conductivity[9].

Use of nanotechnology to improve performance in used

The aim of using nanotechnology in textile applications are low chemical usage, low energy costs and less change in physical and mechanical original properties such as a handle, strength, and air permeability, also it provides the fibers new functional properties.[5, 10].

The use of nanotechnology in the textile finishing is fast growing in the recent years. Nanosize materials may enhance the physical properties of textiles such as antibacterial properties, selfcleaning, ultraviolet protection, hydrophobic, fire retardant properties... etc. $[3,10]$ Nanomaterial which uses frequently in textile is silver, silicon dioxide, titanium dioxide, zinc oxide, copper, gold,....etc[11, 12].

Production of antimicrobial textile goods has raised because of growing demand for comfortable, clean, and hygienic textile fabrics. ${ }^{[13]}$ Results showed that the antimicrobial finishes have negatively affected on the fabric properties, as tensile, and bending was greatly affected by the treatments while roughness and surface friction and compression showed only slight impairments. In addition to, wash fabrics up to 25 times could still retain certain microbial resistance, but 50 times showed no antimicrobial properties, also, the treatments were not effective to be used as antimicrobial finishes on cotton fabrics [14]. For add antibacterial properties for fabric, Nano-sized silver, titanium dioxide and zinc oxide is used. It inhibits the multiplication and growth of those bacteria and fungi which cause infection, odor, itchiness, and sores [13, 15].

Nanosilver is a powerful and natural antimicrobial agent that has been proven highly effective in fighting a whole range of microbes. $[16,17]$. Nano-silver (nano-Ag), provides many advantages:

- Suitable for all textiles - environmentally friendly • Easy handling - Harmless to skin • Washing stable up to $40^{\circ} \mathrm{C} \cdot$ Dry cleaning resistant - Ironing resistant. - Long lasting protection for textiles against water, dirt, and grease - Texture, and breathability of the material remains[16, 17].

The self-cleaning property is desirable for many textile applications because they can be 
water-repellent, stain-resistant, etc[18]. a selfcleaning surface thus results since the rolling water droplets across the surface can easily pick up the dirt particles to leave behind a clean surface[19].

$\mathrm{TiO}_{2}$ nanoparticles have unique properties such as higher stability, long lasting, safe and broad-spectrum antibiosis. This makes $\mathrm{TiO}_{2}$ nanoparticles applicable in many fields such as self-cleaning, antibacterial agent and UV protecting agent $[20,21]$. Titanium dioxide $\left(\mathrm{TiO}_{2}\right)$ is nontoxic and chemically stable under exposure to both high temperatures and UV[22]. .After treatment, there is less than 5\% decrease in textile strength and tearing strength, the air permeability of the fabric remains unchanged, and washing durability of the coatings is also good[23]. Selfcleaning surfaces treated with nanomaterial can result in saving detergents and energy.

Skin contact with dermal titanium and zinc oxides cannot cause any serious risk because they cannot penetrate into the skin (epidermal layer).
Consequently, they cannot reach the blood[23].

\section{Stabilization of nanoparticles}

The problem achieves a textile finish in such a way that the intended function is maintained over long-term, and in particular resistant to the mechanical and thermal stress of the laundry care. Another problem with the Nano finishes is the preservation of the haptic properties (grip, flexibility) of the fabric. Except that, the Nano finishing represents a non-negligible cost factor[24].

There are two kinds of stabilization procedures: electrostatic stabilization by the surface adsorbed anions, and steric stabilization by the presence of bulky groups[25].

\section{Experimental}

\section{Specifications of produced fabrics}

To evaluate the effect of treatment fabrics, on the performance of end-use fabrics, 3 samples were produced as listed in Table 1. For all samples,

TABLE 1. The specifications of produced samples.

\begin{tabular}{|c|c|c|c|c|c|c|c|}
\hline $\begin{array}{c}\text { Sample } \\
\text { no. }\end{array}$ & $\begin{array}{c}\text { Warp } \\
\text { material }\end{array}$ & $\begin{array}{c}\text { Weft } \\
\text { material }\end{array}$ & $\begin{array}{c}\text { Warp } \\
\text { density/cm }\end{array}$ & $\begin{array}{c}\text { Picks } \\
\text { density/cm }\end{array}$ & $\begin{array}{c}\text { Count of } \\
\text { warp yarns }\end{array}$ & $\begin{array}{c}\text { Count } \\
\text { of weft } \\
\text { yarns }\end{array}$ & $\begin{array}{c}\text { Weave } \\
\text { structures }\end{array}$ \\
\hline
\end{tabular}

the warp material was cotton, its yarn count was $50 / 2 \mathrm{Ne}$ and warp density was $36 / \mathrm{cm}$. On the other hand, weft materials were cotton, rayon viscose, and bamboo, yarn count for bamboo, cotton, and rayon were 32 / 2 Ne. Wefts densities were 20 picks $/ \mathrm{cm}$. All fabrics were woven by a plain $1 / 1$ weave.

\section{Treatment of the Fabrics \\ Materials}

1, 2, 3, 4-butane tetracarboxylic acid (BTCA), sodium hypophosphite (SHP) and nanotitanium dioxide P25 powder were provided by Degussa. Carboxymethylcellulose (CMC) having high molecular weight $(\mathrm{Mw}=10,000 \mathrm{Da})$, silver nitrate were of laboratory grade chemicals.

\section{Synthesis of Ag nanoparticles}

The definite weight of CMC was dissolved in distilled water using heating magnetic stirrer. After complete dissolution, the $\mathrm{pH}$ of the solution was adjusted within the range 6-12.5, followed by raising the temperature of the reaction medium to the desired temperature $90^{\circ} \mathrm{C}$. A Certain amount of silver nitrate solution was then added dropwise (keeping in mind that the total volume of the reaction mediumis $100 \mathrm{~cm}^{3}$ ). The reaction mixture was kept under continuous stirring for different durations (15min). A short time after addition of silver nitrate, the reaction medium acquires a clear yellow brown color indicating the formation of silver nanoparticles. The progression of the reaction was controlled by UV-vis absorption; aliquots from the reaction bulk were withdrawn at given time intervals and evaluated.

\section{Treatment of fabrics}

An aqueous solution of 1, 2, 3, 4 butane tetracarboxylic acid $[30 \mathrm{~g} / \mathrm{l}]$ and sodium hypophosphite $\left[\mathrm{NaH}_{2} \mathrm{PO}_{2} . \mathrm{H}_{2} \mathrm{O}\right][2 \% \mathrm{~W} / \mathrm{W}]$ based on the weight of [BTCA]. Different fabric samples (cotton, cotton /bamboo blend, and cotton/viscose blend) were padded in the prepared solution in two dips and nips then squeezed to a wet pick - up of $100 \%$. The padded fabrics were dried at $80 \mathrm{C}^{\circ}$ for $5 \mathrm{~min}$.

Pretreated BTCA fabrics were coated with Egypt.J.Chem. 61, No.4 (2018) 
the nanoparticles in three different sequences: 1) coating of fabric with $1 \% \mathrm{TiO}_{2}$ nanoparticles and Ag nanoparticles in the same bath, 2) coating of fabric by $1 \% \mathrm{TiO}_{2}$ post-treated by Ag nanoparticles, 3) coating of fabric by $\mathrm{Ag}$ nanoparticles posttreated with $-1 \% \mathrm{TiO}_{2}$ ). All fabrics were padded in two dip and nip and then squeezed to a wet pick-up of $100 \%$. Padded fabrics were dried at $80^{\circ} \mathrm{C}$ for $10 \mathrm{~min}$ and then cured at 130 for $3^{\circ} \mathrm{C}$ min. Cured fabrics were finally washed for 10 min in order to remove the nanoparticles having no bonding reaction with the fabrics.

\section{Characterization}

Transmission electron microscope (TEM)

Particle shape and size were obtained with a JEOL-JEM-1200. Specimens for TEM measurements were prepared by dissolving a drop of colloid solution on a 400 mesh copper grid coated by an amorphous carbon film and evaporating the solvent in air at room temperature.

\section{Evaluation of antibacterial activity}

Antibacterial activity of treated cotton fabrics was evaluated using Agar Plate Method. The coated fabrics were performed with Gram-positive bacteria (S. aureus and Bacillus cereus), Gramnegative bacteria (E. coli and P. aeruginosa) and fungi (Candida albicans).

\section{Photocatalytic studies}

Evaluation of photocatalytic degradation of methylene blue (MB)

Degradation of adsorbed $\mathrm{MB}$ on cotton fabric treated with $\mathrm{TiO}_{2}$ nanoparticles and $\mathrm{Ag}$ nanoparticles in the same bath, fabric coated with $\mathrm{TiO}_{2}$ post-treated with $\mathrm{Ag}\left(\mathrm{TiO}_{2}-\mathrm{Ag}\right.$ treated fabric) nanoparticles as well as, Ag nanoparticles treated fabrics post-treated by $\mathrm{TiO}_{2}$ nanoparticles (Ag $-\mathrm{TiO}_{2}$ treated fabric), have been investigated. In detail, nine pieces of treated fabrics $(0.5 \mathrm{gm}$.) were placed in $100 \mathrm{ml}$ beakers containing 50 $\mathrm{ml}$ of aqueous solutions of MB (10 mg/l). The beakers were then exposed to normal laboratory environmental conditions for $10 \mathrm{hr}$ under shaking. The rate of decolorization of colorant solutions was recorded to the change in the intensity of absorption peak of MB in the visible region. UV-Vis absorption spectra of the colorant solutions treated fabrics were recorded. For comparison, the same test was also performed using untreated fabrics.

\section{Evaluation of photocatalytic degradation of $M B$ coated fabrics \\ Photocatalytic activity of treated fabrics with $\mathrm{TiO}_{2}$ nanoparticles and $\mathrm{Ag}$ nanoparticles in the same bath, $\left(\mathrm{TiO}_{2}-\mathrm{Ag}\right.$ treated fabric) as well as (Ag - $\mathrm{TiO}$ treated fabric) were also investigated through the fabric self-cleaning of MB dye stains. Self-cleaning takes place at the surface of fabrics exposed to direct sunlight for nearly $12 \mathrm{hr}$.}

\section{Testing and Analysis}

The experimental tests have been achieved in the weave laboratory in the National Institute for standards in Harm Giza and laboratory of in a standard environment (relative moisture: $65+2$, Temperature $\left.20^{\circ} \mathrm{C}+2\right)[26]$. Treated samples were tested for Pema test (skin model) and Stability of treatment to washing test[27].

Results of the experimental tests carried out on samples under study are statistically analyzed for data listed and relationships between variables were obtained.

TABLE 2. Results of Samples test.

\begin{tabular}{|c|c|c|c|c|c|c|}
\hline $\begin{array}{c}\text { Thermal } \\
\text { conductivity } \\
\text { (cal/s.cm.K) }\end{array}$ & $\begin{array}{c}\text { Air } \\
\text { permeability } \\
\left(\mathrm{sec} / \mathrm{cm}^{\gamma} / \mathrm{cm}^{r}\right)\end{array}$ & $\begin{array}{c}\text { Relative } \\
\text { water-vapor } \\
\text { Permeability(\%) }\end{array}$ & $\begin{array}{l}\text { Weight } \\
(g / m 2)\end{array}$ & $\begin{array}{c}\text { textile } \\
\text { material }\end{array}$ & Treatment & Number \\
\hline 0.29 & 10.52 & 50.7 & 214.69 & rayon & & 1 \\
\hline 0.35 & 10.48 & 49.5 & 204.22 & Bamboo & Both (1) & 2 \\
\hline 0.28 & 11.66 & 49.1 & 209.44 & Cotton & & 3 \\
\hline 0.21 & 8.07 & 48.9 & 219.66 & rayon & & 4 \\
\hline 0.38 & 11.66 & 53.5 & 207.83 & Bamboo & $\mathrm{Ag}-\mathrm{TiO}_{2}(2)$ & 5 \\
\hline 0.31 & 14.04 & 50 & 207.63 & Cotton & & 6 \\
\hline 0.38 & 13.56 & 47.9 & 186.75 & rayon & & 7 \\
\hline 0.3 & 13.54 & 54.9 & 201.3 & Bamboo & $\mathrm{TiO}_{2}-\mathrm{Ag}(3)$ & 8 \\
\hline 0.18 & 9.55 & 49.8 & 211.73 & Cotton & & 9 \\
\hline
\end{tabular}

Where 1,2,3 cotton/viscose, cotton /bamboo and cotton fabric treated with $\mathrm{TiO}_{2}$ nanoparticles and Ag nanoparticles in the same bath, 4,5,6cotton/viscose, cotton /bamboo and cotton fabric with Ag nanoparticles post-treated with $-1 \%$ TiO 2 and 7,8,9 cotton/viscose, cotton /bamboo and cotton fabric treated with $\mathrm{TiO}_{2}$-followed by Ag nanoparticles solution. 


\section{Results and Discussion}

The transmission of air, heat and water vapor through fabrics are probably the most important factors in textile comfort. Results of the experimental tests carried out on samples after treatment are presented in the following tables and graphs.



Fig. 1. Radar chart of the properties of cotton treated fabric in different ways.

Determination of the best treatment for each material based on its end used properties

The best treatment for Cotton fabric
It is clear from Table 2 and Fig. 1 that the best treatment for the cotton fabric is $\mathrm{Ag}-\mathrm{TiO}_{2}$ (2), as it gave the best results for properties that fit the

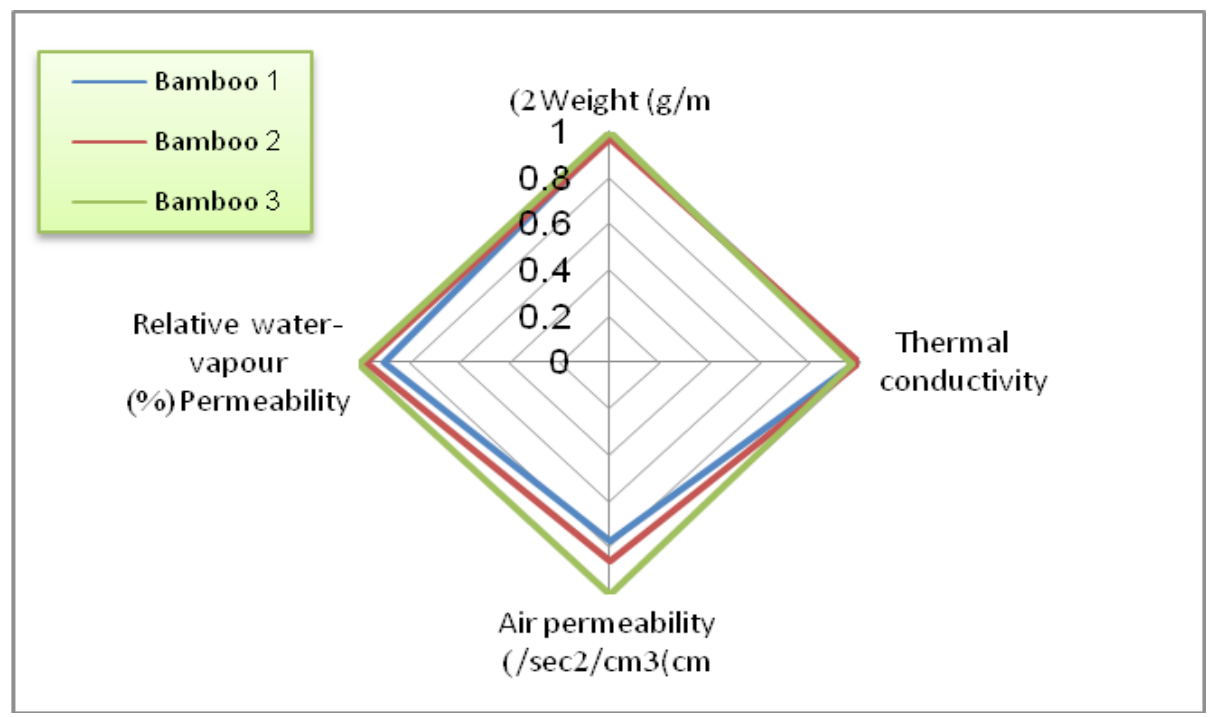

Fig. 2. Radar chart of the properties of Bamboo treated fabric in different ways.

purpose of end use. It is followed by both (1) and in the last $\mathrm{TiO}_{2}-\mathrm{Ag}(3)$.

The best treatment for Cotton / bamboo fabric It is clear from Table 2 and Fig. 2 that the best treatment for the cotton /bamboo fabric is $\mathrm{TiO}_{2}-$ $\mathrm{Ag}$ (3) as it gave the best results for properties that fit the purpose of end use. It is followed by $\mathrm{Ag}-\mathrm{TiO}_{2}(2)$ and in the last both (1)

The best treatment for Cotton/viscose(rayon) fabric

It is clear from Table 2 and Fig. 3 that the best treatment for the cotton/viscose fabric is $\mathrm{TiO}_{2}-\mathrm{Ag}$ Egypt.J.Chem. 61, No.4 (2018) 




Fig. 3. Radar chart of the properties of rayon viscose treated fabric in different ways.

(3) as it gave the best results for properties that fit the purpose of end use. It is followed by both (1) and in the last $\mathrm{Ag}-\mathrm{Tio}_{2}(2)$.

Determination of the best treatment and material

It is clear from Table 2 and Fig. 4 that cotton and a little less cotton /bamboo are the best materials, achieved the high-performance efficiency for the purpose of use, to reduce the likelihood of being infected with the bed sores, where they gave the best properties directly associated with the comfort after treatment with nanotechnology.

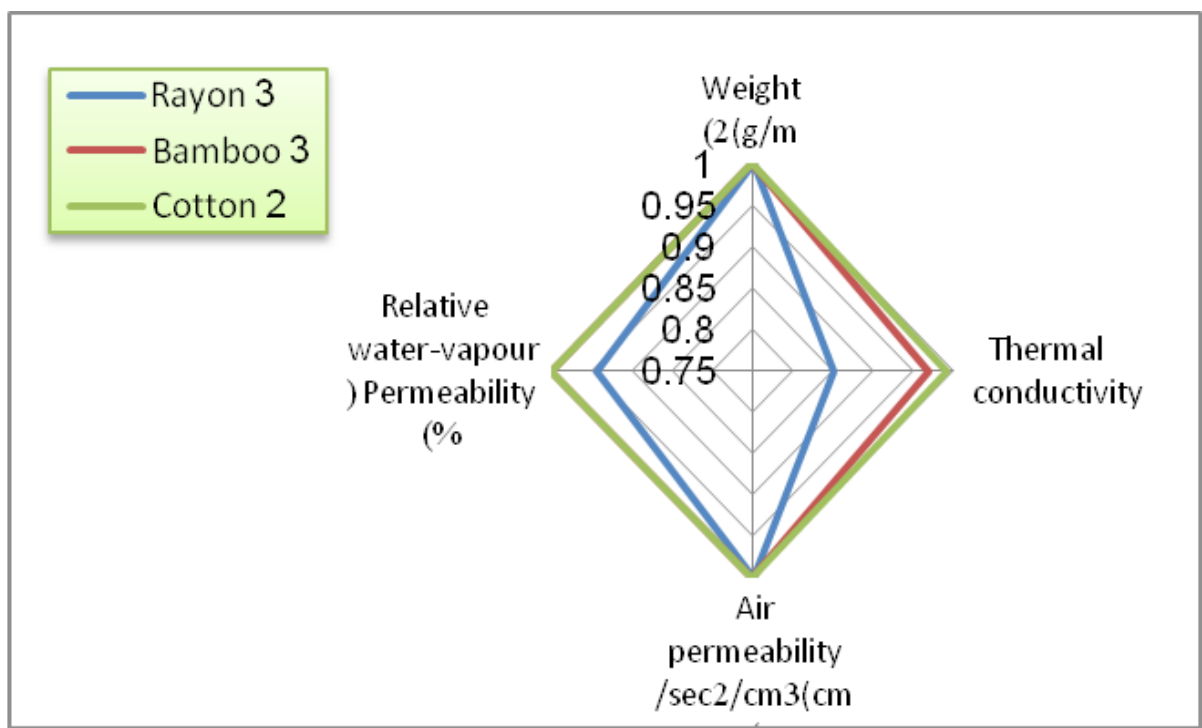

Fig.4. Radar chart of the properties of treated materials in different ways.

The stability of treatments for washing

Synthesis of Ag nanoparticles

Successful attaining of silver nanoparticles is investigated by UV-vis absorption (Fig. 5a) and TEM (Fig. 5b) as shown in Figure 5a, the absorption peaks appear at $425 \mathrm{~nm}$ which represent typical Plasmon resonance band of
Ag-NPs. The micrographs of TEM signify that AgNPs are prepared in spherical shape even with well-distributed particles of small sizes as they lie in the range of 5-30 $\mathrm{nm}$.

Photocatalytic degradation of methylene blue Figure 6 shows the UV-vis absorption spectra 


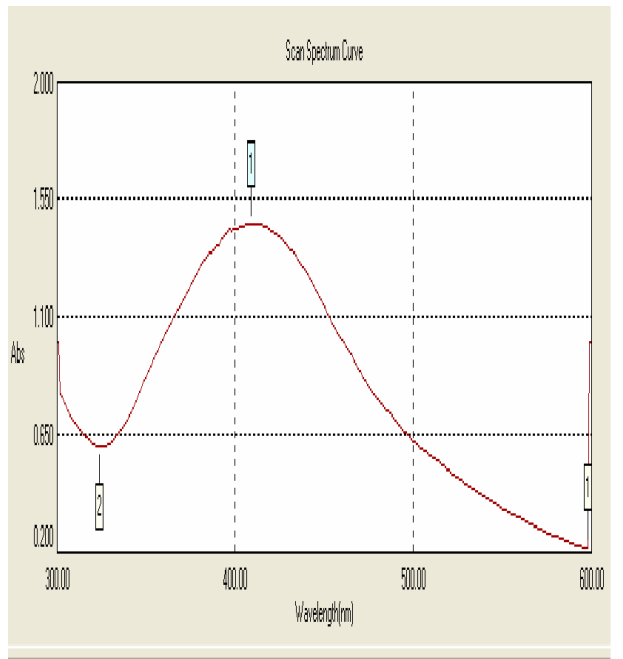

Fig. 5a. UV-vis spectra of (a) silver nanoparticles.

of decolorization of methylene blue $(10 \mathrm{mg} / \mathrm{l})$ under normal visible light for treated samples using a different sequence of treatments The spectral changes brought by degradation of $\mathrm{MB}$ adsorbed on the different treated. The decrease in the concentration of the colorant Methylene Blue dye after exposure to UV irradiation is recorded by the change in the intensity of absorption peak in the visible region samples. As shown in the figure, the major peak for MB dye was observed at

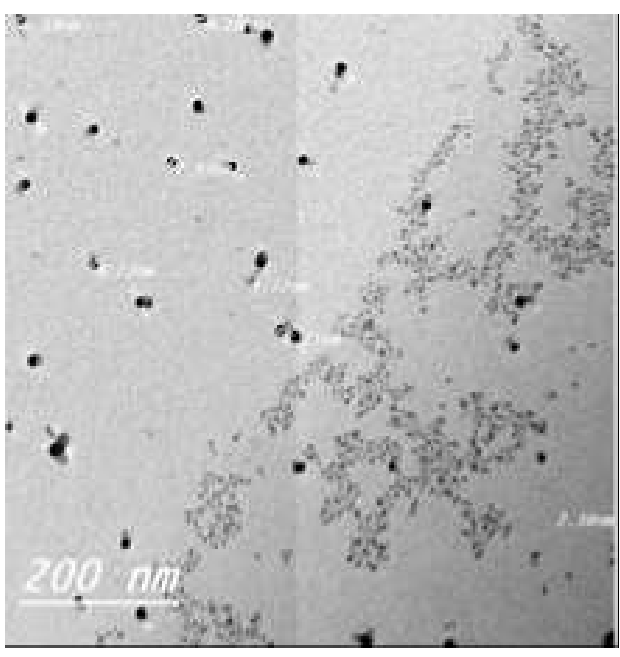

Fig. 5b. TEM image of the silver nanoparticles.

$\lambda$ max, i.e., $645 \mathrm{~nm}$ with high intensity. It was also observed that the intensities of peak decrease with a high degree for the cotton /bamboo, cotton as well as cotton/viscose treated samples indicating high photocatalytic activities. The cotton /bamboo treated samples recorded better self-cleaning function.

Figure 7 shows the self-cleaning and degradation of the dye on the blank and treated cotton fabric stained with $\mathrm{MB}$ dye (10 g/l)

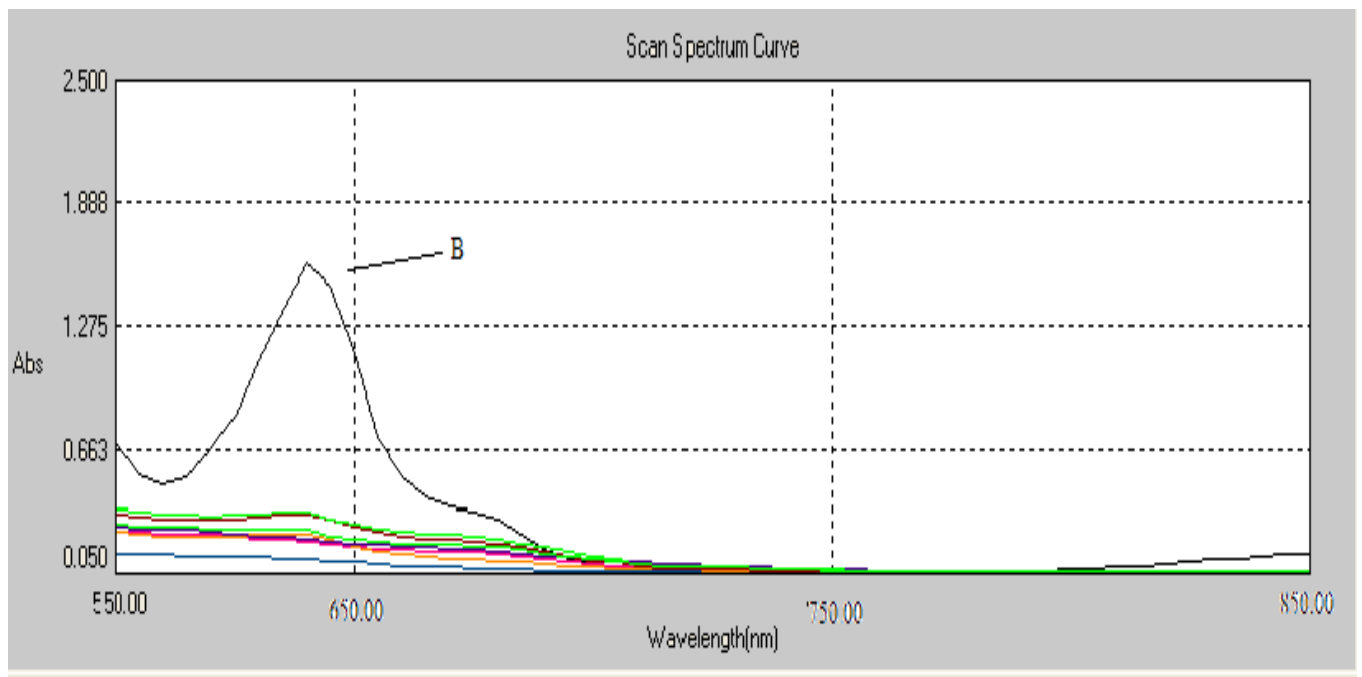

Fig. 6. UV-vis absorption spectra of decolorization of methylene blue (10 mg/l) under normal visible light.

where c, b, f are blank cotton ,cotton /bamboo and cotton/viscose -1,2,3 cotton/viscose, cotton /bamboo and cotton fabric treated with $\mathrm{TiO}_{2}$ nanoparticles and $\mathrm{Ag}$ nanoparticles in the same bath, 4, 5, 6, cotton/viscose,cotton /bamboo and cotton fabric with $\mathrm{Ag}$ nanoparticles post-treated with $-1 \% \mathrm{TiO}_{2}$ and 7, 8, 9 cotton/viscose,cotton /bamboo and cotton fabric treated with $\left(\mathrm{TiO}_{2}\right.$-followed by $\mathrm{Ag}$ nanoparticles solution $)$ 
when subjected to direct sunlight for12 hrs. Photocatalytic activity of fabrics coated with $\mathrm{TiO}_{2}$ nanoparticles was evaluated through the fabric self-cleaning of MB dye stains. Self-cleaning takes place at the treated cotton/viscose, cotton as well as cotton /bamboo fabric surface under normal laboratory conditions as shown in Fig. 7. The energy of UV was employed to activate the photocatalytic decomposition of dye stains by titanium dioxide particles. By exposing the stained samples to normal laboratory conditions, the photocatalytic properties of titanium dioxide altered the molecular configuration of stains turning them into colorless. It was observed that all treated samples show high efficiency towards removal of $\mathrm{MB}$ dye stains. The cotton /bamboo treated samples are the most effective towards the self-cleaning feature.

- Photoexcitation of semiconductor surfaces induces the creation of an electron-hole pair.

- Some electron-hole pairs are recombined, the remaining holes contribute to the oxidation reactions by generating

- $\mathrm{OH}$, radicals.

- Oxygen is reduced as an electron acceptor to superoxide and this leads to production

taking bacteria Bacillus subtilis and Staphylococcus aureus as $(\mathrm{G}+\mathrm{ve})$ model bacteria. (G+ve) while Escherichia coli and Pseudomonas aeruginosa are taken as (G-ve) model bacteria

As shown in Fig. 8, 9 all treated fabric were found to possess excellent antibacterial abilities even after 10 washing cycles. It was also concluded that:

1. Treatment of fabrics by $\mathrm{TiO}_{2}$ post-treated by silver nanoparticles solution shows of $\mathrm{HO}_{2}$

- Radical this finally plays a strong oxidant role. All these possible reactions contribute to increasing the degradation and decolorization of MB dye.

Evaluation of antibacterial activity

We performed an antibacterial experiment

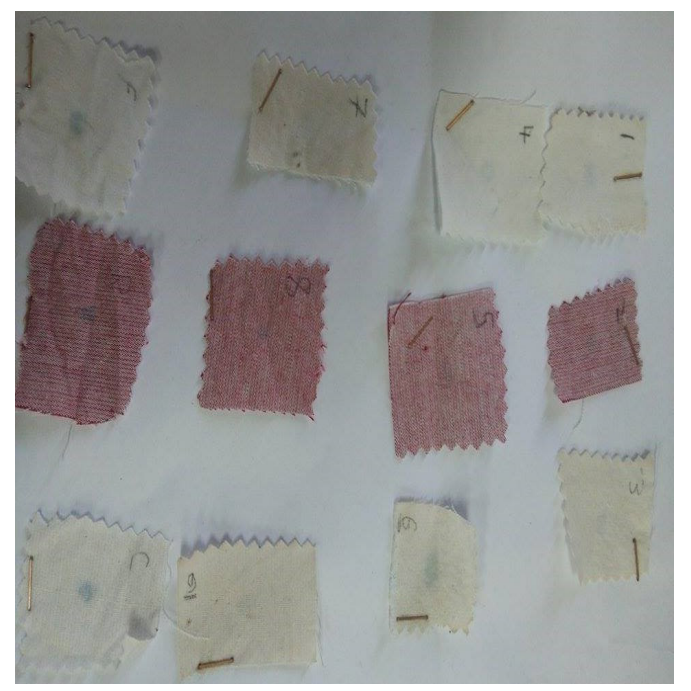

Fig. 7. Decolorization of MB dyes stained on treated samples

higher antibacterial results than other two sequences of treatments.

2. Cotton /bamboo treated samples exhibited more significant efficacy against bacteria. Therefore, the treated fabric believed to have great potential for use as antibacterial fabrics.

The researchers recommend studying the effect of those treatments on the basic properties of the fabrics associated with the direction of the property of comfort.



Fig. 8. The samples slightly affected after one washing. 


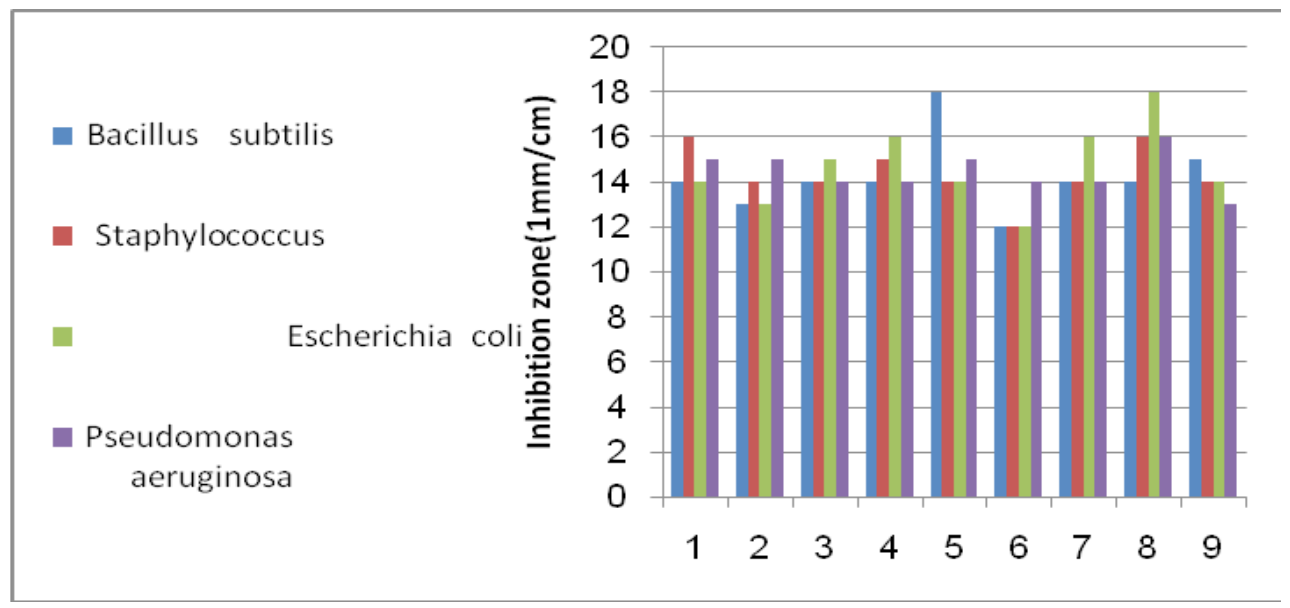

Fig. 9. The samples slightly affected by repetition of washing process.
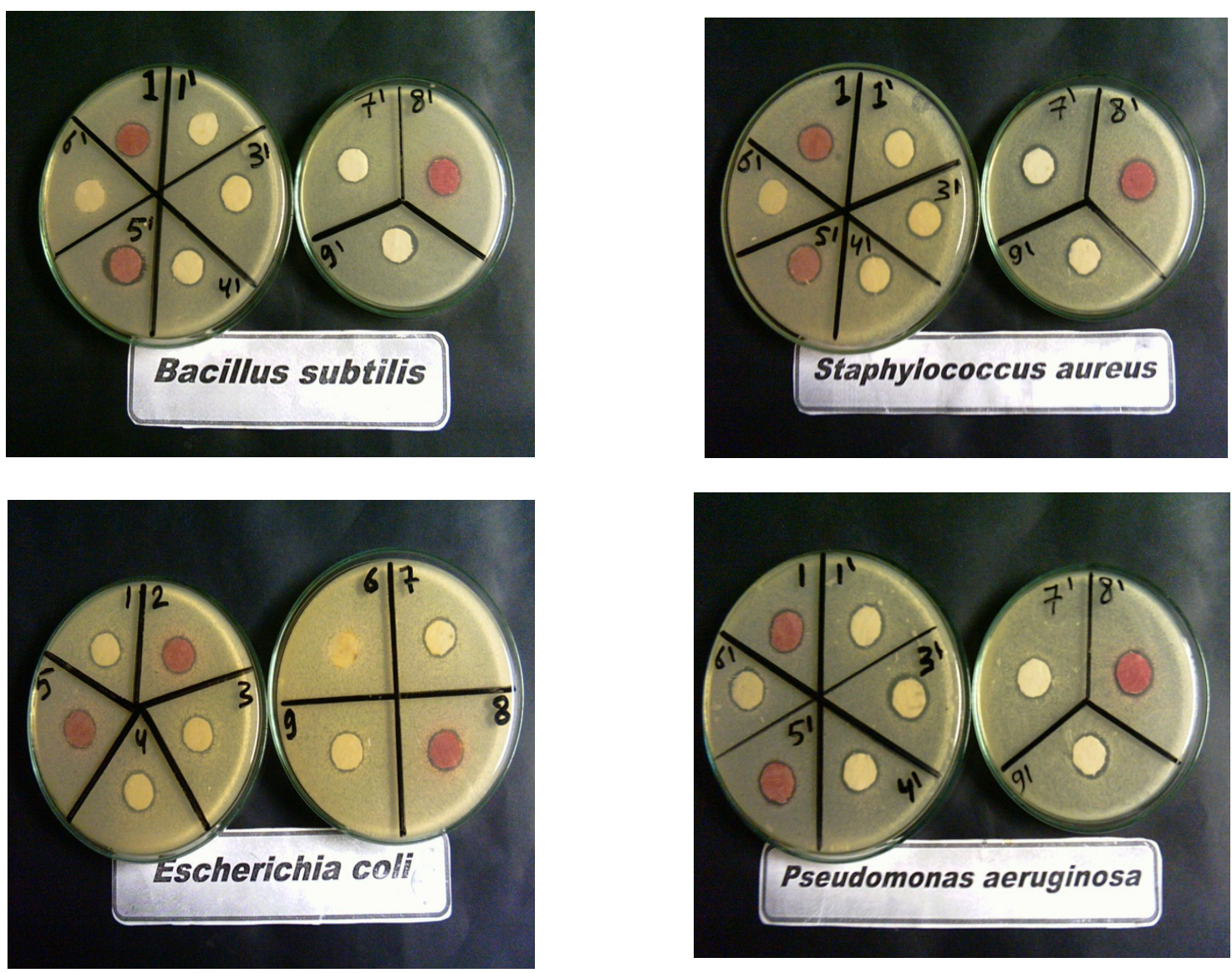

Fig. 10. Photographs of the antibacterial test results of treated fabrics.

\section{Conclusion}

The aim of this research is to achieve the best functional characteristics of the bed sheets which used in hospitals. Three samples were produced from cotton, cotton/viscose iond cotton /bamboo. Fabrics were treated by Nanosilver, and Nano
Titanium dioxide to be resistant to bacteria so resist bed sores as well and have the ability to Self-Cleaning. The results show that:

1. Cotton and cotton /bamboo are the best treatment materials, achieved the high-performance efficiency for the purpose of use, where they gave the best

Egypt.J.Chem. 61, No.4 (2018) 
properties directly associated with the comfort (water vapor permeability, air permeability, and thermal conductivity), after treatment with nanotechnology.

2. Treatment of fabrics by $\mathrm{TiO}_{2}$ post-treated by silver nanoparticles solution shows higher antibacterial results than other two sequences of treatments.

3. Cotton / bamboo treated samples exhibited more significant efficacy against bacteria. Therefore, the treated fabric believed to have great potential for use as antibacterial fabrics.

4. All treated samples show high efficiency towards removal of MB dye stains. Cotton /bamboo treated samples are the most effective one towards the self-cleaning feature.

As a result, open spaces in the fabric reduce.

\section{References}

1. Kothari V., Thermo-physiological comfort characteristics and blended yarn woven fabrics. (2006).

2. Barakat O., Nassar K., Abou-Taleb E.M., The effect of construction of Sheet fabrics to resist the bed sores. International Journal of Advance Research in Science and Engineering (IJARSE); 6 (2017).

3. Chattopadhyay R., Design of Apparel Fabrics: Role of fibre, yarn and fabric parameters on its functional attributes. Journal of Textile Engineering; 54, 17990 (2008).

4. Kaplan S., Orris J.P., Machi R., A research agenda for advancing patient, worker and environmental health and safety in the health care sector. Health Care Without Harm Retrieved; 29, 2010 April (2009).

5. El-Khatib E., Antimicrobial and Self-cleaning Textiles using Nanotechnology. Res J Text Apparel; 16, 156-74 (2012).

6. Wong Y., Yuen C., Leung M., Ku S., Lam H., Selected applications of nanotechnology in textiles. AUTEX Res J; 6, 1-8 (2006).

7. Saad E.R., Hafez N.M., Effect of coating with silver nanoparticles (AgNPs) on cotton fabric functional properties. Int Des J; 4, 33-9 (2014).

8. De Smet D., Vanneste M., Leppchen-Fröhlich K., Meyer M., Renewable antimicrobials for textile finishing. Melliand Inter (2015).
9. Matusiak M., Sikorski K., Influence of the structure of woven fabrics on their thermal insulation properties. Fibres \& Textiles in Eastern Europe; 19, 88 (2011).

10. Tenhagen B., Käsbohrer A., Fetsch A., Bräunig J., Appel B., Bundesinstitut für Risikobewertung. Fachgruppe Epidemiologie, Zoonosen und Antibiotikaresistenz (2011).

11. Hebeish A., El-Shafei A., Sharaf S., Zaghloul S., In situ formation of silver nanoparticles for multifunctional cotton containing cyclodextrin. Carbohydr Polym; 103, $442-7$ (2014).

12. El-Hady M.A., Farouk A., Sharaf S., Flame retardancy and UV protection of cotton based fabrics using nano $\mathrm{ZnO}$ and polycarboxylic acids. Carbohydr Polym; 92, 400-6 (2013).

13. Hebeish A., El-Shafei A., Sharaf S., Zaghloul S., Development of improved nanosilver-based antibacterial textiles via synthesis of versatile chemically modified cotton fabrics. Carbohydr Polym; 113, 455-62 (2014).

14. Sharaf S., Higazy A., El Aref A.T., Refai R., Development of Medical Reusable Gowns Using Eco-Friendly Finishing Agents. International Journal of Advanced Research; 3, 589-605(2015).

15. Afzali A., Maghsoodlou S., Modern application of nanotechnology in textile. Nanostructured Polymer Blends and Composites in Textiles, 41-85(2016).

16. Arafa A.S., Sanad S.H., Bahloolsh O. Nanotechnology application on cotton fibers, yarn and fabric and its impact on their qualities and antimicrobial resistance. Egyptian Journal of Agricultural Research; 92, 153-66 (2014).

17. Uddin F., Environmental concerns in antimicrobial finishing of textiles. International Journal of Textile Science; 3, 15-20 (2014).

18. Patra J.K., Gouda S., Application of nanotechnology in textile engineering: An overview. Journal of Engineering and Technology Research; 5, 104-11 (2013).

19. Yong J., Yang Q., Chen F., Zhang D., Farooq U., Du G., et al. A simple way to achieve superhydrophobicity, controllable water adhesion, anisotropic sliding, and anisotropic wetting based on femtosecond-laser-induced line-patterned surfaces. Journal of Materials Chemistry A; 2, 5499-507 (2014).

20. Sundaresan K., Sivakumar A., Vigneswaran C., 
Ramachandran T., Influence of nano titanium dioxide finish, prepared by sol-gel technique, on the ultraviolet protection, antimicrobial, and selfcleaning characteristics of cotton fabrics. $J$ Indust Text; 41, 259-77 (2012).

21. Farouk A., Sharaf S., El-Hady M.A., Preparation of multifunctional cationized cotton fabric based on $\mathrm{TiO}_{2}$ nanomaterials. Int $J$ Biol Macromol; 61, 230-7 (2013).

22. Kathirvelu S., D’souza L, Dhurai B., UV protection finishing of textiles using $\mathrm{ZnO}$ nanoparticles. (2009).

23. Joshi M., Bhattacharyya A., Nanotechnology-a new route to high-performance functional textiles. Textile Progress; 43, 155-233 (2011).
24. Rovira J., Nadal M., Schuhmacher M., Domingo J.L., Human exposure to trace elements through the skin by direct contact with clothing: Risk assessment. Environ Res; 140, 308-16 (2015).

25. Marková B., The application of a responsible approach to nanoresearch. Zeszyty Naukowe Organizacja i Zarządzanie/Politechnika Śląska (2016).

26. Gibson P., Rivin D., Kendrick C., SchreuderGibson H., Humidity-Dependent Air Permeability of Textile Materials1. Text Res J; 69, 311-7 (1999).

27. Huang J., Qian X., Comparison of test methods for measuring water vapor permeability of fabrics. Text Res J; 78, 342-52 (2008).

(Received 12/2/2018; accepted 13/6/2018)

\footnotetext{
بالمستشام تقياتية النانو لتحقيق أفضل الخواص الوظيفيه لاقمثة الملاعات المستخدمه

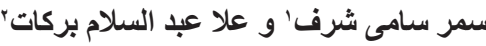

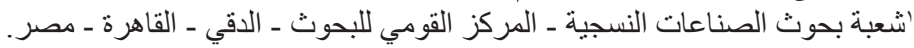

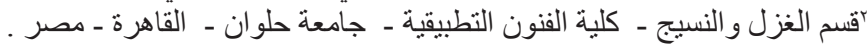

يهدف هذا البحث إلى تحقيق أفضل الخصائص الوظيفية لملاءات الاسرة المستخدمة بالمستشفيات ، لتكون مقاومة

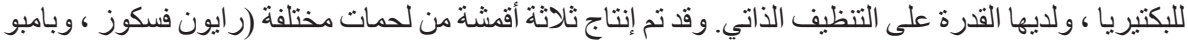

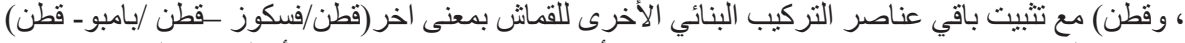

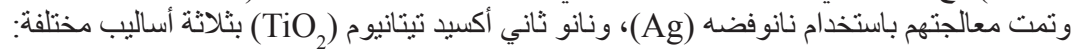

( ) معالجة النسيج (coating) بنسبة ( ) من جسيمات متناهية الصغرمن ثانى اكسيد التنتانيوم TiO وجسيمات نانوية من الفضة في نفس الحمام.

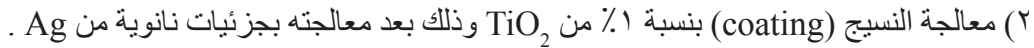
ץ) معالجة النسيج (coating) بنسبة ( من من م وذللك بعد معالجته بجزئيات نانوية من TiO

وقد تم اختبار العينات المعالجة باختبار Pema (محاكي الجلد)، والذي يتم فية إختبار كل من نفاذية القماش

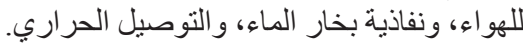

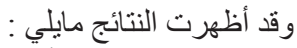

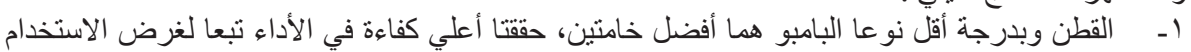

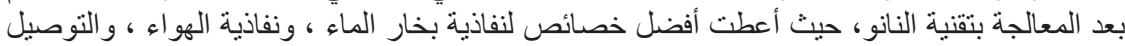

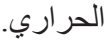
r- معالجة الأقمشة بو اسطة TiO

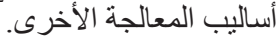

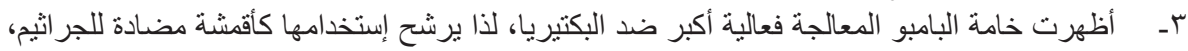

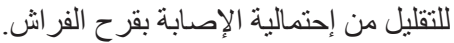

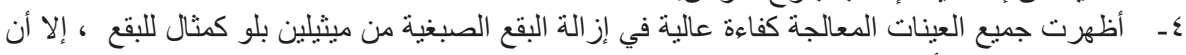
البامبو كان هو الأكثر فعالية تجاه خاصية التنظيف الذاتي.
} 